\title{
A Novel Approach for Subretinal Implantation of Ultrathin Substrates Containing Stem Cell-Derived Retinal Pigment Epithelium Monolayer
}

\author{
Yuntao Hu ${ }^{a}$ e Laura Liu ${ }^{a, f}$ Bo Lu ${ }^{c}$ Danhong Zhu ${ }^{a, b}$ Ramiro Ribeiro ${ }^{a, g}$ \\ Bruno Diniz $^{\mathrm{a}, \mathrm{h}}$ Padmaja B. Thomas ${ }^{\mathrm{a}}$ Ashish K. Ahuja ${ }^{\mathrm{a}}$ David R. Hinton ${ }^{\mathrm{a}}$ b \\ Yu-Chong Tai ${ }^{c}$ Sherry T. Hikita ${ }^{d}$ Lincoln V. Johnson ${ }^{d}$ Dennis O. Clegg ${ }^{d}$ \\ Biju B. Thomas ${ }^{a}$ Mark S. Humayun ${ }^{a}$
}

${ }^{a}$ Doheny Eye Institute and Department of Ophthalmology and ${ }^{b}$ Department of Pathology, Keck School of

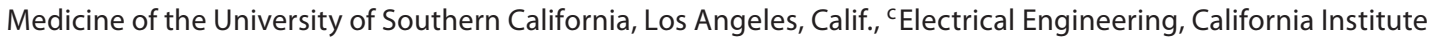
of Technology, Pasadena, Calif., and ${ }^{\mathrm{d} C e n t e r}$ for Stem Cell Biology and Engineering, University of California-Santa Barbara, Santa Barbara, Calif., USA; ' Department of Ophthalmology, Peking University Third Hospital, Beijing, China; ${ }^{f}$ Department of Ophthalmology, Chang Gung Memorial Hospital, Linko, Taiwan, ROC; ${ }^{9}$ Hospital Evangelico de Curitiba, Fepar, Curitiba, and hetina Sector, Universidade Federal de São Paulo, São Paulo, Brazil

\section{Key Words}

Transplantation · Stem cells · Parylene $\cdot$ Retinal pigment epithelium • Royal College of Surgeon rats

\footnotetext{
Abstract

Objective: To evaluate the feasibility of a new technique for the implantation of ultrathin substrates containing stem cell-derived retinal pigment epithelium (RPE) cells into the subretinal space of retina-degenerate Royal College of Surgeon (RCS) rats. Methods: A platform device was used for the implantation of 4- $\mu \mathrm{m}$-thick parylene substrates containing a monolayer of human embryonic stem cell-derived RPE (hESC-RPE). Normal Copenhagen rats $(n=6)$ and RCS rats $(n=5)$ were used for the study. Spectral-domain optical coherence tomography (SD-OCT) scanning and histological examinations were performed to confirm placement location of the implant. hESC-RPE cells attached to the substrate before and after implantation were evaluated using stan-
}

dard cell counting techniques. Results: SD-OCT scanning and histological examination revealed that the substrates were precisely placed in the rat's subretinal space. The hESCRPE cell monolayer that covered the surface of the substrate was found to be intact after implantation. Cell counting data showed that less than $2 \%$ of cells were lost from the substrate due to the implantation procedure (preimplantation count $2,792 \pm 74.09$ cells versus postimplantation count $2,741 \pm 62.08$ cells). Detailed microscopic examination suggested that the cell loss occurred mostly along the edges of the implant. Conclusion: With the help of this platform device, it is possible to implant ultrathin substrates containing an RPE monolayer into the rat's subretinal space. This technique can be a useful approach for stem cell-based tissue bioengineering techniques in retinal transplantation research.
Copyright $\odot 2012$ S. Karger AG, Basel

\section{KARGER}

Fax +4161306 1234

E-Mail karger@karger.ch

www.karger.com
(C) 2012 S. Karger AG, Basel

$0030-3747 / 12 / 0484-0186 \$ 38.00 / 0$

Accessible online at:

www.karger.com/ore
Biju B. Thomas, $\mathrm{PhD}$

Doheny Eye Institute

1355 San Pablo St., DVRC 402

University of Southern California, Los Angeles, CA 90033 (USA)

Tel. +1 323442 6691, E-Mail bthomas@ doheny.org 


\section{Introduction}

Several retinal degeneration diseases currently reported are irreversible, and no treatment strategies are available to completely cure these diseases. Cell-based therapies have a great potency to cure some of these diseases by means of tissue engineering-based techniques [1]. Studies performed by various investigators suggest that stem-cell based treatment strategies have the potency to cure diseases affecting the retinal ganglion cells and the optic nerve [2,3], retinal pigment epithelium (RPE) $[4,5]$ and photoreceptors $[6,7]$.

Stem cells, with their capacity to differentiate and replace diseased cells, could be a good source for RPE cell transplantation $[8,9]$. In a normal retina, RPE cells maintain polarity and remain as a monolayer. In the majority of the previous investigations, stem cell-derived RPE transplantation was performed by injecting dissociated cells as a suspension [5]. We are able to culture RPE cells derived from human embryonic stem cells (H9) on ultrathin parylene substrates as a polarized monolayer. The RPE monolayer thus obtained can be a suitable source for replacement therapies in the eye. However, ultrathin substrates are usually too soft to implant as a flat sheet in the subretinal space. For this, we developed a novel approach to perform successful placement of ultrathin substrates containing human embryonic stem cellderived RPE (hESC-RPE) cells in the subretinal space of Royal College of Surgeon (RCS) rats. The RCS rat is considered as an acceptable model for human RPE dysfunction diseases.

\section{Materials and Methods}

\section{Animals}

Normal Copenhagen rats (Charles River Laboratories International Inc., Wilmington, Mass., USA; 28-30 days old, $n=6$ ) and dystrophic RCS rats (Dr. Matthew LaVail rodent colonies, Beckman Vision Center, University of California, San Francisco, Calif., USA; 28-30 days old, $\mathrm{n}=5$ ) were used for subretinal implantation surgeries. Copenhagen rats were used for cell counting studies (before and after implantation), while RCS rats were used for detailed morphological evaluation of the retina 1 week after implantation. The animals were immunosuppressed by intraperitoneal injection of dexamethasone $(1.6 \mathrm{mg} / \mathrm{kg} / \mathrm{day})$ and oral cyclosporine (administered through drinking water, $210 \mathrm{mg} / \mathrm{l}$ ) starting 2 days before implantation and continuing until the end of the experiment. Rats were maintained under a 12-hour light/ dark cycle. All animals were maintained in accordance with the ARVO statement for the use of animals in research, and the research was approved by the Animal Care and Use Committee of the University of Southern California.

Subretinal Implantation of Ultrathin

Substrates

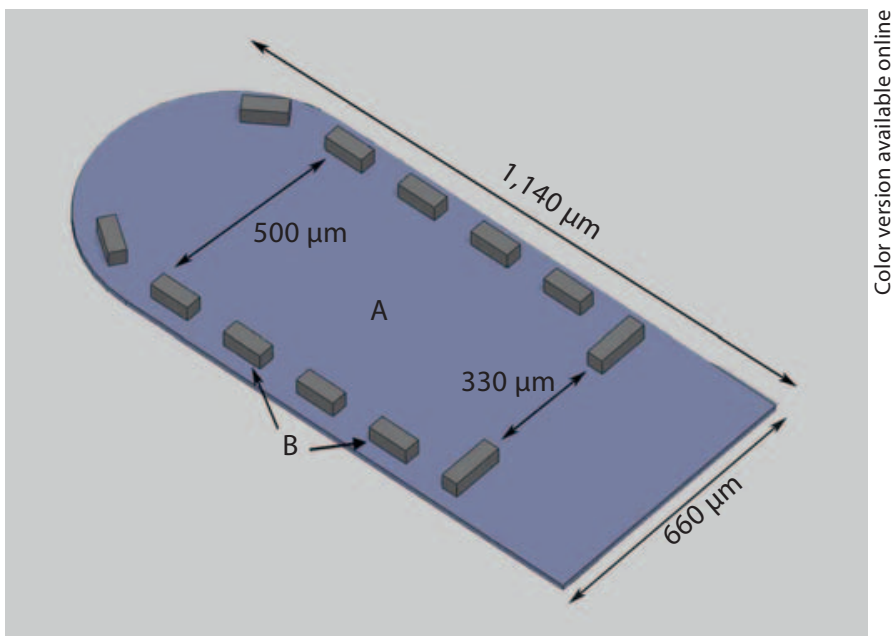

Fig. 1. Diagrammatic sketch of the implantation tool. The device consists of a thin parylene plate (A) containing barriers (B) arranged in the form of a ' $U$ '. The substrate for implantation is placed in the middle of the U-shaped area (substrate chamber).

\section{Substrates and Stem Cells}

Human embryonic stem cells (H9; Wicell, Madison, Wisc., USA) were spontaneously differentiated into RPE cells as described previously $[10,11]$. These hESC-RPE cells were cultured and maintained in serum-free medium (X-VIVO 10, Lonza, Walkersville, Md., USA) on Synthemax plates (Corning, Corning, N.Y., USA). Based on staining with RPE markers, cultures were greater than 95\% RPE. Passage 2 hESC-RPE cells were dissociated with trypLE (Invitrogen, Carlsbad, Calif., USA) and seeded on ultrathin substrate films made of parylene $(0.4 \times 0.9 \mathrm{~mm}, 4 \mu \mathrm{m}$ thickness) coated with matrigel (BD Biosciences, Franklin Lakes, N.J., USA) at a cell density of $10^{5} / \mathrm{cm}^{2}$. The cells were then maintained in culture on the ultrathin parylene substrates for 4 weeks with the medium changed twice weekly.

\section{Platform Device}

The platform device made of parylene (10 $\mu \mathrm{m}$ thick) contained barriers (30 $\mu \mathrm{m}$ high) arranged along the edges in the shape of a ' $U$ ' (fig. 1). The space inside the barriers acted as the 'substrateloading chamber' where the substrate for implantation was placed.

\section{Surgical Procedure}

After the conjunctiva had been opened, extraocular muscles were maintained on traction for eyeball fixation. A small incision (approx. 0.8-1.0 $\mathrm{mm}$ ) was cut transsclerally at the temporal equator of the host eye until the choroid was exposed. Puncture of the anterior chamber released some of the aqueous humor to reduce intraocular pressure. About $5 \mu \mathrm{l}$ balanced salt solution was injected through a 32-gauge steel needle into the subretinal space to create a focal retinal detachment. The choroid was cut with fine scissors while the retina remained intact. During implantation, the substrate containing hESC-RPE cells was loaded on the platform device with the surface of the substrate coated with cells facing upwards. The platform, along with the substrate, was held 
with fine forceps and gently pushed into the subretinal space through the choroidal incision. During this process, the cells on the surface of the substrate always faced the vitreous side of the retina. The substrate was released into the subretinal space by holding it in place using the forceps and gently pulling the platform device out of the eye through the incision. Once the placement of the implant was confirmed, based on microscopic fundus examination, the incision was sutured (10-0 nylon surgical suture, REF 03199, S\&T, Neuhausen, Switzerland), and antibiotic drops were applied on the eye. The animals were allowed to recover in a thermal care incubator.

Cell Counting and Statistical Analysis Using Copenhagen Rats

Photographic images of the substrate were captured before implantation using a phase contrast microscope. Copenhagen rats were sacrificed immediately after implantation, and the substrates were dissected out after enlarging the scleral and choroidal incisions. Images of the substrate were captured after fixation with $10 \%$ formaldehyde. A grid pattern was superimposed on the images to divide a single substrate into 40 small squares using Microsoft Power Point, and the images were printed out. Three small square areas on a single substrate were randomly picked for manual cell counting. The average of the cell numbers counted from the three areas was multiplied by 40 to determine the total cell number on the single substrate. Cell counting was performed by 4 independent evaluators, and the final cell numbers for the substrate were the average numbers from the 4 evaluators. Statistical comparison of the cell counting data (before and after implantation) was performed using Student's t test (Graph Pad Prism 5.0, La Jolla, Calif., USA).

\section{Spectral-Domain Optical Coherence Tomography}

Examination and Histological Evaluation Using RCS Rats

Immediately after implantation, the location of the implant was verified using spectral-domain optical coherence tomography (SD-OCT; Spectralis HRA+OCT, Heidelberg Engineering Inc., Heidelberg, Germany). The RCS rats were subjected to another SD-OCT examination before termination (1 week after implantation). The eyes were enucleated, fixed and embedded in paraffin for histological examination. Sections (5 $\mu \mathrm{m}$ thick) were stained with hematoxylin and eosin for light-microscopic evaluation.

\section{Results}

\section{Surgery}

The substrate can be easily loaded inside the platform device between the vertical barriers. The barriers prevent the implant from moving away from the chamber during the implantation process. After surgery, the retina remained intact and no vitreous leakage was observed. No signs of subretinal hemorrhage or lens damage were observed.

\section{Cell Counting}

The total number of hESC-RPE cells on the substrate before implantation averaged 2,792 \pm 74.09 cells/sub-

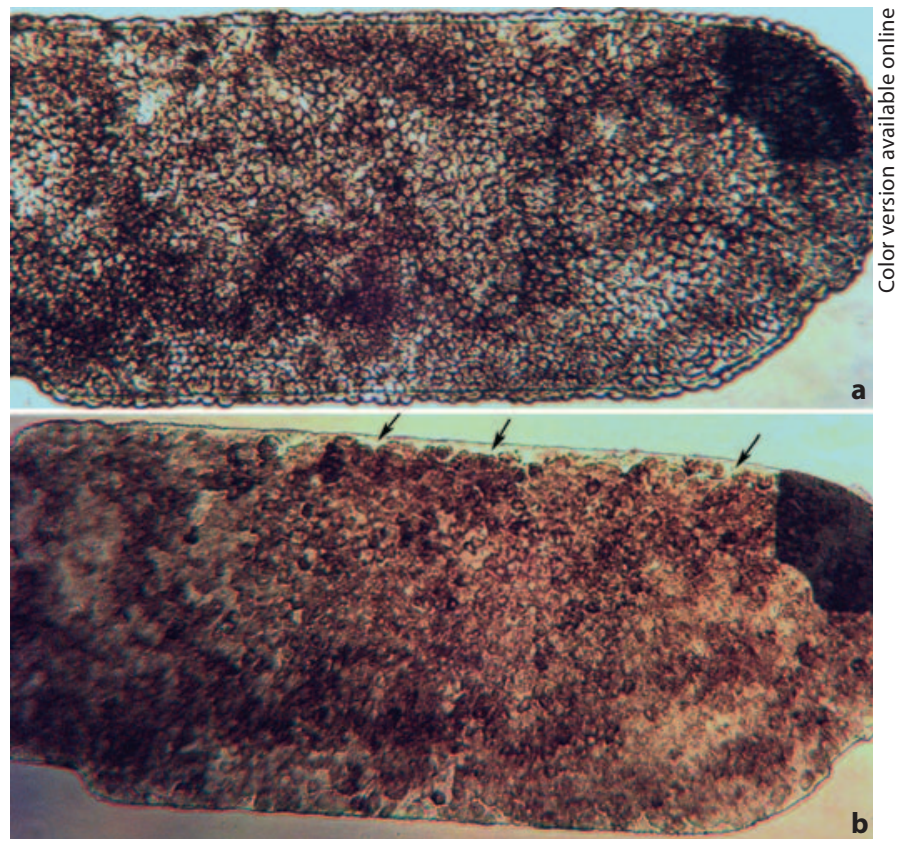

Fig. 2. The ultrathin substrate containing hESC-RPE cells. Images were taken before (a) and after (b) subretinal implantation. b Considerable cell loss can be observed along the edges of the substrate (arrows).

strate. After implantation, the cell numbers were 2,741 \pm 62.08 cells/substrate $(\mathrm{p}<0.05$, table 1$)$. This amounted to approximately $98 \%$ retention of the cells. Detailed microscopic examination revealed that the RPE monolayer structure was well preserved in all implanted substrates, with small cell loss (no more than 2\%) observed only along the edges (fig. 2).

\section{SD-OCT Examination}

Immediately after implantation, SD-OCT scanning revealed focal retinal detachment at the site of implantation as expected. In all animals, the substrate was placed as a flat sheet adjacent to Bruch's membrane. The SDOCT examination performed in RCS rats 1 week after implantation showed subretinal placement of the implant and reattachment of the retina (fig. 3).

\section{Histology}

In corroboration of the SD-OCT data, microscopic examination of the histology sections revealed that substrates were precisely placed in the subretinal space as a flat sheet. The hESC-RPE cell monolayer remained intact (fig. 4), and no retinal trauma or damage to Bruch's membrane was observed. 


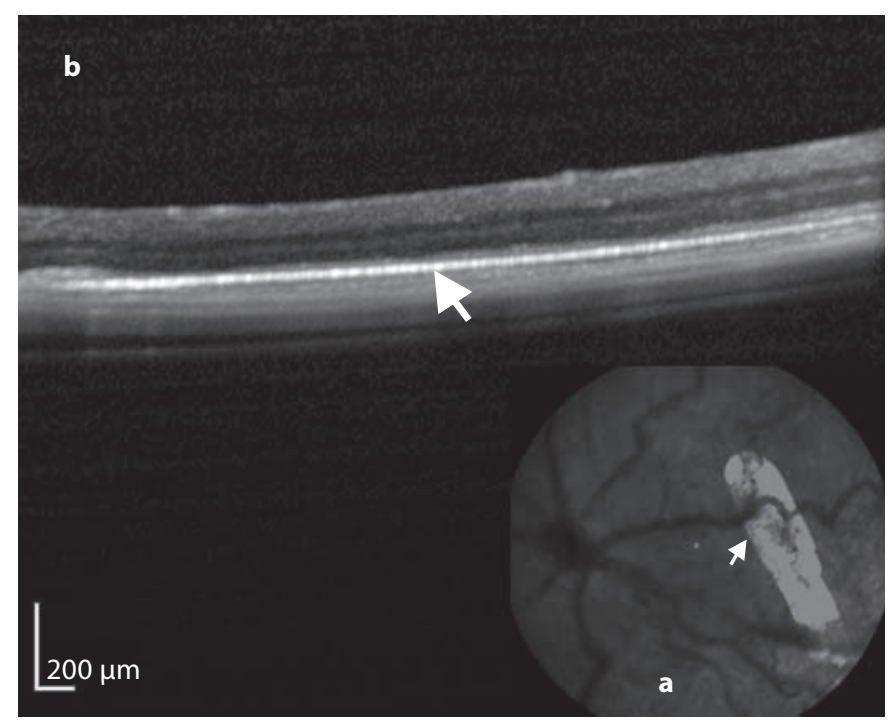

Fig. 3. a Fundus image showing the substrate implanted in the rat's eye. b SD-OCT scanning image of the substrate (arrow) containing hESC-RPE cells implanted in the rat subretinal space.

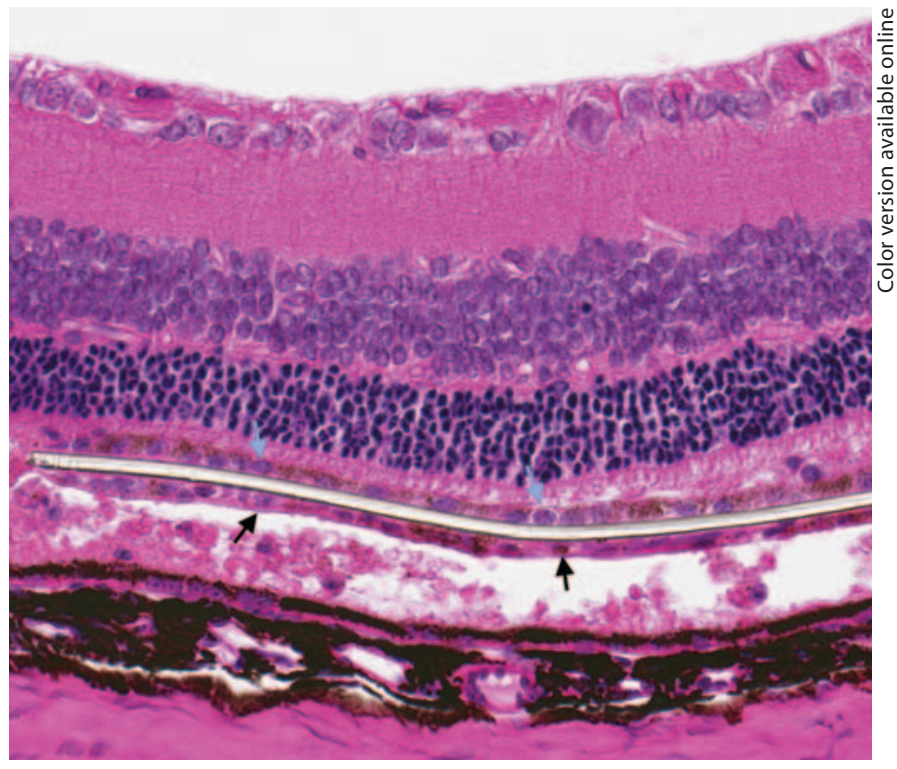

Fig. 4. Hematoxylin- and eosin-stained section passing through the implanted area. The substrate contains hESC-RPE cells on the top (blue arrow). Some hESC-RPE cells that were grown under the substrate can be found on the bottom side (black arrow). $\times 40$. Color refers to the online version only.

Table 1. hESC-RPE cell numbers on substrates before and after subretinal implantation

\begin{tabular}{llllllll}
\hline Assessment & 1 & 2 & 3 & 4 & 5 & 6 & Mean $^{ \pm} \mathrm{SD}^{1}$ \\
\hline Preoperative & $2,677.5$ & $2,740.5$ & 2,800 & $2,803.5$ & $2,852.5$ & $2,880.5$ & $2,792 \pm 74.09$ \\
Postoperative & $2,654.5$ & $2,683.8$ & $2,742.8$ & $2,753.3$ & $2,803.8$ & $2,807.5$ & $2,741 \pm 62.08$ \\
\hline \multicolumn{1}{c}{$\mathrm{p}=0.0006(<0.05) ; \mathrm{t}=7.694$, d.f. $=5}$. & & & & & \\
\hline
\end{tabular}

\section{Discussion}

Although the dissociated cell injection technique is an easy approach for delivering cells into the subretinal area, transplantation of hESC-RPE, grown on the substrate as a monolayer, is a more desirable method for tissue engineering-based therapeutic intervention in the eye. The majority of the current RPE transplantation procedures involves injection of the dissociated RPE cells as a suspension. Cell suspension injections may lead to the formation of isolated cell clumps that fail to develop into a polarized RPE monolayer structure [12-14]. Moreover, these nonpolarized cells, when placed in the subretinal space, may remain nonfunctional; they may eventually die or initiate immunological reactions. This suggests that it is important to implant an already functionally polarized RPE monolayer to develop successful treatment strategies.

During transplantation procedures, it is important that a suitable implantation tool is used for subretinal placement of the graft. Several previous investigators demonstrated the use of specially designed tools for implantation studies involving larger animals in which a vitreous approach was employed for subretinal placement [15-17]. Considering the small size of the rodent eye, a transscleral approach is required for successful placement of the implant in the subretinal space. Aramant and Seiler [18] used a specially designed tool to implant fetal 
retinal sheets into the subretinal implantation of rats and mice. In their procedure, a sheet of fetal retina is sucked inside a small nozzle, and the nozzle tip is inserted into the subretinal space where the sample is released. This tool is made of stiff materials and consists of a cannula used for loading the substrate. During insertion of the cannula for subretinal placement of the graft, the surgeon cannot see the tip of the cannula; hence, there is the possibility of damaging the neural retina, choroid and even optic nerve [19]. Butterwick et al. [20] developed a fork implantation tool containing grooves for subretinal prosthesis implantation in rats, but the above tool may not be suitable for implantation of soft ultrathin substrates.

Our transplantation tool (platform device) is made of parylene and is specifically designed for subretinal implantation of ultrathin substrates (fig. 1). The device can be easily loaded with the hESC-RPE graft (ultrathin parylene containing hESC-RPE). Considering the small size of the rat eye, a transscleral approach was required for subretinal placement of the graft. The thin and flexible nature of the platform device enabled access to the subretinal space without causing considerable damage to the retina and the choroid. Barriers on the surface of the device prevented the substrate moving away from the surface. The platform protects the cells from potential damage caused by potential surgical shear force. When the substrate was reexamined following implantation, a loss of less than $2 \%$ of the hESC-RPE was observed. Detailed microscopic evaluation revealed that the cell loss occurred mostly along the edges of the substrate. Considering the potential therapeutic benefits, loss of $<2 \%$ of the cells, especially from the edges of the substrate, may not be very critical. Histological evaluation performed after implantation suggested that an intact RPE monolayer is preserved in the remaining area over the substrate.

Most of the previous instruments used for rat retinal transplantation surgeries induce large retinal detachments that may result in retinal folding during reattachment. With the help of our platform device, it is possible to perform subretinal implantation without creating large retinal detachments. Since the mechanical strength of the implantation device is low, the possible damage to the retinal tissue or Bruch's membrane during insertion will be less.

In summary, the above factors and our supporting data in this study suggest that this new platform device can be considered as a safe and useful tool for the implantation of organized sheets of retinal cells with guaranteed appropriate orientation in the subretinal space. The size of the platform can be adjusted to fit the size of the substrate and, hence, can be used for larger animals, such as pigs, and even in the clinic for transplantation surgeries in human patients.

\section{Acknowledgements}

We wish to thank our colleagues Zhenhai Chen, Xiaopeng Wang, Rongjuan Wu, Gilberto Raul Lopez, Juan Carlos Gutierrez, Juan Carlos Martinez and Rodrigo Brant, who made significant contributions to this research, and Gerald J. Chader and Susan Clarke for manuscript editing. This research was supported by CIRM DRI-01444, Research to Prevent Blindness and NEI grant EY03040.

\section{References}

1 Limb GA, Daniels JT, Cambrey AD, Secker GA, Shortt AJ, Lawrence JM, Khaw PT: Current prospects for adult stem cell-based therapies in ocular repair and regeneration. Curr Eye Res 2006;31:381-390.

2 Dahlmann-Noor A, Vijay S, Jayaram H, Limb A, Khaw PT: Current approaches and future prospects for stem cell rescue and regeneration of the retina and optic nerve. Can J Ophthalmol 2010;45:333-341.

3 Harper MM, Grozdanic SD, Blits B, Kuehn MH, Zamzow D, Buss JE, Kardon RH, Sakaguchi DS: Transplantation of BDNF-secreting mesenchymal stem cells provides neuroprotection in chronically hypertensive rat eyes. Invest Ophthalmol Vis Sci 2011;52: 4506-4515.
4 Wang S, Lu B, Girman S, Duan J, McFarland T, Zhang QS, Grompe M, Adamus G, Appukuttan B, Lund R: Non-invasive stem cell therapy in a rat model for retinal degeneration and vascular pathology. PLoS One 2010; 5:e9200.

5 Schwartz SD, Hubschman JP, Heilwell G, Franco-Cardenas V, Pan CK, Ostrick RM, Mickunas E, Gay R, Klimanskaya I, Lanza R: Embryonic stem cell trials for macular degeneration: a preliminary report. Lancet 2012;379:713-720.

6 Lamba DA, McUsic A, Hirata RK, Wang PR, Russell D, Reh TA: Generation, purification and transplantation of photoreceptors derived from human induced pluripotent stem cells. PLoS One 2010;5:e8763.
7 Lamba DA, Gust J, Reh TA: Transplantation of human embryonic stem cell-derived photoreceptors restores some visual function in Crx-deficient mice. Cell Stem Cell 2009;4: 73-79.

8 Baker PS, Brown GC: Stem-cell therapy in retinal disease. Curr Opin Ophthalmol 2009;20:175-181.

$\checkmark 9$ Lee E, Maclaren RE: Sources of retinal pigment epithelium (RPE) for replacement therapy. Br J Ophthalmol 2011;95:445-449.

10 Buchholz DE, Hikita ST, Rowland TJ, Friedrich AM, Hinman CR, Johnson LV, Clegg DO: Derivation of functional retinal pigmented epithelium from induced pluripotent stem cells. Stem Cells 2009;27:24272434. 
11 Rowland TJ, Blaschke AJ, Buchholz DE, Hikita ST, Johnson LV, Clegg DO: Differentiation of human pluripotent stem cells to retinal pigmented epithelium in defined conditions using purified extracellular matrix proteins. J Tissue Eng Regen Med 2012, E-pub ahead of print.

12 Lu L, Yaszemski MJ, Mikos AG: Retinal pigment epithelium engineering using synthetic biodegradable polymers. Biomaterials 2001;22:3345-3355.

13 Phillips SJ, Sadda SR, Tso MO, Humayan MS, de Juan E Jr, Binder S: Autologous transplantation of retinal pigment epithelium after mechanical debridement of Bruch's membrane. Curr Eye Res 2003;26:81-88.
4 Shiragami C, Matsuo T, Shiraga F, Matsuo N: Transplanted and repopulated retinal pigment epithelial cells on damaged Bruch's membrane in rabbits. Br J Ophthalmol 1998; 82:1056-1062.

15 Gosh F, Arner K: Transplantation of fullthickness retina in the normal porcine eye. Retina 2002;22:478-486.

16 Thumann G, Aisenbrey S, Schaefer F, BartzSchmidt KU: Instrumentation and technique for delivery of tissue explants to the subretinal space. Ophthalmologica 2006; 220:170-173.

17 Stanzel BV, Liu Z, Brinken R, Braun N, Holz FG, Eter N: Subretinal delivery of ultrathin rigid-elastic cell carriers using a metallic shooter instrument and biodegradable hydrogel encapsulation. Invest Ophthalmol Vis Sci 2012;31:490-500.
18 Aramant RB, Seiler MJ: Retinal transplantation. Sci Med 2000;7:20-29.

19 Seiler MJ, Rao B, Aramant RB, Yu L, Wang Q, Kitayama E, Pham S, Yan F, Chen Z, Keirstead HS: Three-dimensional optical coherence tomography imaging of retinal sheet implants in live rats. J Neurosci Methods 2010;188:250-257.

20 Butterwick A, Huie P, Jones BW, Marc RE, Marmor M, Palanker D: Effect of shape and coating of a subretinal prosthesis on its integration with the retina. Exp Eye Res 2009;88: 22-29. 